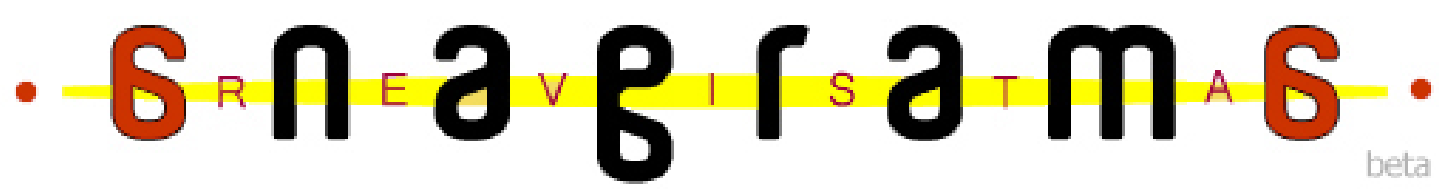

\section{A Juventude na mídia Brasileira: estereótipos e ekclusão}

\section{Fernanda Coelho da Silua'}

\section{Resumo}

O tema da democratização da comunicação é cada vez mais discutido no país, porém, as relações que se estabelecem entre mídia e público não caminham rumo à democratização. A relação da mídia brasileira com as minorias, neste trabalho em especial a juventude, é bastante complexa. O jovem, especialmente o negro, pobre e morador da periferia, não tem, via de regra, o seu direito à comunicação respeitado. Tal afirmação é justificada no texto que se segue a partir de exemplos tirados da própria mídia.

Palauras-Chaue: Cidadania. Comunicação democrática. Direitos sociais. Juventude. Mídia.

\section{1- Comunicação: direito negligenciado}

Atualmente muito tem se falado em democratização da comunicação. Mas o que significa isso? Democratizar a comunicação significa garantir o acesso de todos à recepção e à emissão de produtos de comunicação. Desde 1960 a UNESCO já trata do direito à comunicação. Na década de 70 surge a Ordem Mundial de Comunicação (OMIC), ressaltando que o direito a comunicação seria um direito humano, de liberdade e um avanço democrático, porém a OMIC não obteve repercussão.

Em 2001, na cidade de Genebra, esse debate é retomado com a criação do CRIS (Communication Rights in the Information Society), no Brasil ficou conhecido como Direito à Comunicação na Sociedade Informacional. O principal objetivo do CRIS é convocar a sociedade civil para essa discussão. Seu auge foi em 2003, ano em que esse tema é resgatado com muita força pela academia e pelos movimentos sociais.

Atualmente as discussões sobre direitos humanos no Brasil passam por mudanças. Eles deixaram de se limitar à questão da violência e da segurança pública. As organizações

\footnotetext{
${ }^{1}$ Fernanda Coelho da Silva é graduanda em Comunicação Social pela Universidade Federal de Juiz de Fora. Participa de um grupo de pesquisa na linha de comunicação e identidade e é bolsista de iniciação científica (PIBIC-CNPQ) do Projeto Rádios Comunitárias autorizadas em Juiz de Fora e Participação juvenil, sob a coordenação e orientação da prof ${ }^{a}$. Dr ${ }^{\mathrm{a}}$. Cláudia Regina Lahni. fernandahauck@yahoo.com.br.
} 
da sociedade civil começam a trazer os direitos humanos econômicos, sociais e culturais para o seio das discussões de direitos humanos tradicionais. Avança-se no sentido de resgatar a Conferência de Viena (1993), que afirmou a indivisibilidade e universalidade dos direitos.

Desta forma, tratar os direitos civis e políticos como direitos de primeira geração e os direitos econômicos, sociais e culturais como de segunda geração, passou, não apenas a ser um erro conceitual mas propiciou, sobretudo, a construção de um novo discurso e a possibilidade de um olhar sobre os direitos humanos no Brasil.

Dentre os direitos socioeconômicos mais negligenciados no país está o direito à comunicação. Embora esse direito esteja assegurado na Declaração Universal dos Direitos Humanos e na Constituição Brasileira (1988), muitas vezes, na prática, não funciona. Ter direito à comunicação significa exercer plenamente o direito à cidadania. E, infelizmente, as minorias no Brasil não exercem esse direito plenamente, a exemplo disso temos a juventude brasileira.

\section{2- Juventude em risco}

O histórico de políticas de atendimento a crianças e adolescentes no Brasil revela a negligência e o abandono com que, geralmente, se trata a infância e a juventude no país. De acordo com Viviane Massi (2001), o caminho para se chegar a conquistas como a elaboração do ECA foi longo e árduo. E mesmo depois dessa conquista, os problemas não acabaram. O ECA, além de muitas vezes não ser respeitado também não soluciona todos os problemas de nossos jovens.

A autora explica que desde a chegada dos portugueses ao Brasil até o fím do século XIX o modelo de assistência aos menores foi o caritativo, no qual os abandonados dependiam da caridade e beneficência humanas para sobreviverem. O modelo caritativo não tinha a pretensão de conquistar mudanças sociais e sim de propagar o conformismo dos pobres. As crianças e adolescentes, abandonados e socialmente desfavorecidos, estavam fadados à segregação social, viviam confinados e contidos espacialmente em asilos, tinham seu tempo controlado e eram submetidos às autoridades.

O fim do século XIX e começo do século XX foram marcados pelo acelerado processo de industrialização do país. Houve então a necessidade de utilização da mão-deobra feminina e juvenil. A industrialização gerou crescimento demográfico e urbanização. 
$\mathrm{O}$ crescimento do número de indústrias intensificou a pobreza provocando o aumento do número de habitações precárias, como favelas e cortiços. Havia grande quantidade de crianças e adolescentes maltrapilhos e desamparados.

Após a constituição da República, Massi ressalta que houve uma diferenciação ainda maior entre crianças ricas e pobres. As ricas eram preparadas para dirigir a sociedade, enquanto às pobres restava o trabalho braçal. Havia um aparato médicojurídico-assistencial para prevenir a criminalidade infanto-juvenil, educar para o trabalho e reprimir o "menor delinqüente". O modelo vigente era o de justiça e assistência a crianças e adolescentes infratores e aí surgiu o termo "menor" para designar os desfavorecidos com menos de 18 anos de idade. A responsabilidade do Estado para com a infância e a juventude se limitava a fiscalizar e prover auxílios diversos sem ação direta de assistência, e sim uma parceria com particulares e associações.

Atualmente o que podemos perceber é que o modelo caritativo ainda existe no país. Pois, além de algumas medidas socioeducativas não estarem sendo postas em prática como deveriam, algumas instituições de recuperação de menores não têm atividades pedagógicas, não se preocupam com a escolarização e profissionalização dos jovens e, certas vezes, nem as condições de higiene são adequadas. Algumas medidas são tomadas, como a Bolsa Escola e o Peti (Programa de Erradicação do Trabalho Infantil), mas essas têm caráter paliativo, podem amenizar um problema como o da educação, mas não o solucionam e tão pouco o evitam. As mudanças devem ser estruturais.

A educação deve ser trabalhada de maneira a formar cidadãos, para que as instituições de menores que cometeram atos infracionais tornem-se cada vez menos necessárias e quando necessárias forem, elas devem profissionalizar, educar, trabalhar de forma pedagógica para que esse jovem não reincida no crime. Não é possível recuperar um jovem, com a pretensão de que ele tenha uma vida digna, impondo a ele um regime sem as míninas condições de dignidade. O que os jovens precisam não é caridade é sim, um projeto político de atendimento. O jovem pobre, o jovem negro, o jovem da favela precisa de oportunidades, precisa de inclusão social, de identidade e de atenção do governo e da sociedade.

No artigo Juventude, favelas e os grandes meios de comunicação (2005) Jaílson Oliveira de Sousa aborda o preocupante aumento do número de assassinatos de jovens no nosso país. Entre 1991 e 2000 o aumento dessas mortes foi de 76\%. O fato se agrava quando se trata de jovens negros e de periferia. 
A reportagem "Um tiro no futuro", da revista Carta Capital de dezembro de 2006 (edição 424), assinada por Phydia de Athayde, trouxe dados alarmantes sobre a mortalidade juvenil no país. Dentre as conclusões são destacadas três. A primeira: conquistas como a redução da taxa de mortalidade infantil nas últimas duas décadas podem se anular pelo crescimento de 306\% nas taxas de homicídios de jovens de até 19 anos. A segunda: a perda de jovens no Brasil deixou de ser um problema de segurança pública para se tornar questão de saúde pública. A terceira: a taxa de mortalidade por arma de fogo é de 43,01 por 100 mil jovens entre 15 e 24 anos; em um ranking mundial desse tipo de morte, o Brasil ocuparia o primeiro lugar. Esses números alarmantes estão relacionados a fatores como a desigualdade social e a má distribuição de renda que mantém o país dividido.

Tais dados são da pesquisa Homicídios de Crianças e Jovens no Brasil - 19802002, realizada pelo Núcleo de Estudos da Violência (NEV) da USP. O trabalho, que analisa um intervalo de 22 anos e compara estados e capitais brasileiras, revela que jovens entre 15 e 19 anos são as maiores vítimas de homicídios no país, correspondendo a 87,6\% dos casos. Essas mortes ocorrem essencialmente onde há uma superposição de carências de todos os direitos socioeconômicos e, podemos inferir, que entre eles esteja o direito à comunicação. Outro dado revela que acidentes de trânsito e homicídios são juntos responsáveis por quase $60 \%$ da mortalidade juvenil. Os acidentes de trânsito vitimam $17,1 \%$ e os homicídios causam $39,7 \%$ das mortes de jovens.

A reportagem ainda apresenta constatações que revelam a segregação social e racial que assolam nosso país. As vítimas são fundamentalmente homens negros. Os jovens negros têm um índice de vitimização $85,3 \%$ superior aos brancos. Nessa perspectiva, em que todos parecem que se tornam inimigos, a sociedade tem de encontrar um "bode expiatório": os jovens, os jovens negros que moram na periferia, que são vistos pela sociedade ao mesmo tempo como as grandes vítimas e grandes agentes da violência. A partir daí, Phydia de Athayde levanta uma questão muito importante: os jovens que são mortos nas favelas com certeza não são todos criminosos e mesmo que fossem isso não significa que devessem morrer. A verdade é que o jovem pobre vive em um ambiente conflagrado e, mesmo que não seja criminoso, fatalmente está mais exposto ao crime.

Levando em consideração os dados acima o professor Jaílson Oliveira de Souza sintetiza: ser negro, jovem e morador da periferia ou da favela é portar um kit estigma que gera um risco cotidiano de perder o direito mais fundamental do ser humano, o de sobreviver. Segundo Sousa, encontrar caminhos para combater esse fenômeno talvez seja a 
questão mais relevante para a construção de uma vida mais digna e humana nos grandes centros brasileiros atuais. E na busca de melhor se compreender este fenômeno, cabe levar em devida conta o papel dos grandes meios de comunicação na difusão de uma representação estigmatizante da juventude negra e pobre.

\section{2- mídia e Juuentude}

A mídia, de maneira geral, usa estereótipos para tratar os temas relacionados às minorias no Brasil. Negros, movimentos sociais, mulheres e homossexuais são freqüentemente vítimas de textos jornalísticos preconceituosos. Com a juventude isso não é diferente. E tal situação é ainda agravada quando o jovem é negro e morador da periferia. As favelas são, muitas vezes, colocadas como espaço exclusivo de violência e os jovens negros como seus principais agentes.

No livro Mídia e violência (2007), Silvia Ramos e Anabela Paiva revelam que há um consenso da mídia sobre a cobertura estigmatizante que ela própria realiza sobre favelas e periferia. O dado é de uma pesquisa realizada pelo CESeC (Centro de Estudos de Segurança e Cidadania).

As autoras dizem ainda que mesmo os veículos de imprensa de orientação liberal, advogados da restrição da ação governamental sobre a sociedade, reconhecem que a diminuição da violência depende da implantação de políticas públicas de redução da desigualdade, criação de empregos e educação. Ramos e Paiva continuam:

Mas os jornais, ao enfatizarem quase exclusivamente os conflitos armados e as ocorrências policiais na cobertura dos espaços populares, valorizam as soluções bélicas para o problema da segurança. Muitas reportagens discutem implícita ou explicitamente soluções para isolar e neutralizar as favelas e não para integrálas de forma mais harmônica às grandes cidades. (Paiva e Ramos, 2007: 48).

No artigo Juventude e suas representações na mídia (2007), Mônica Peregrino disserta sobre a complexa relação entre os jovens e a mídia focando na produção e reprodução de processos de identificação juvenis. Peregrino ressalta que a disseminação de informações em escala global é um fenômeno relativamente recente na experiência da humanidade e, portanto, os complexos efeitos desencadeados por essa transformação estão em processo de análise e de discussão.

A autora lembra que desde o final dos anos 80 e principalmente durante os anos 90 , uma série de manifestações (tratadas como "distúrbios" ou como "arruaças") "sacodem" as 
periferias do Novo e do Velho Mundo. Tais manifestações surgiram na França, na Inglaterra, nos guetos americanos, nas favelas brasileiras e em muitas outras periferias. Além da cobertura da mídia mundial, em geral bastante preconceituosa, essas periferias têm algo em comum: todas elas envolvem jovens pobres, envolvidos em processos sociais muito mais profundos e amplos que o tratamento dado pelos meios de comunicação pode nos fazer crer. Como já vem sendo apontado por alguns autores, as coberturas jornalísticas não têm mostrado essas, que em síntese podem ser definidas como ações liminares, ou seja, expressões da vivência cotidiana de situações limite.

Centralizando nossa discussão nas favelas e periferias brasileiras, verificamos um processo apontado por Peregrino: esses lugares, ao serem desconectados, separados dos processos sociais que lhes deram origem, passam a ser vistos como manifestações de "pura violência", "irracionalidade". Aqui a mídia tem papel determinante, ela produz e reforça estereótipos, contribuindo para que os jovens moradores da periferia sejam vistos como violentos, como infratores.

Segundo Aline Silva Correa Maia, no artigo Jovens e Mídia: da periferia da cidade para o centro da página policial (2007), os mais espetaculares e marginais aspectos da cultura juvenil são os pontos de vista que, prioritariamente, interessam aos media, colaborando, por sua repetição, para fazer da juventude uma construção social que existe mais como representação do que como realidade. A partir daí a pesquisador questiona que lugar a mídia reserva à juventude moradora dos subúrbios das cidades.

Maia dá como exemplo da forma que a mídia expõe a juventude da periferia brasileira o filme Cidade de Deus (2002), de Fernando Meirelles e co-direção de Kátia Lund. Segundo a autora nesse filme constrói-se um discurso sobre a realidade na qual se acentua que o papel do jovem da periferia está restrito, em geral, ao banditismo e à marginalidade.

Aline explica que o desenrolar da obra revela a reconstrução de lembranças e a construção de uma memória comunitária, a memória da Cidade de Deus, através das histórias contadas por Buscapé - todas envolvendo, de alguma forma, jovens, transgressão e drogas.

Sendo o processo narrativo importante ferramenta para a estruturação das identidades, entendemos que mesmo tratando-se de uma obra de ficção, as representações de juventude contidas em Cidade de Deus reverberam preconceitos enraizados no imaginário coletivo brasileiro. (Maia, 2007:8) 
Aline conclui sua análise sobre o filme dizendo que além de reforçar os papéis sociais conferidos aos jovens da periferia, Cidade de Deus apresenta desfecho que ratifica a falta de opção para a classe subalterna frente à sua realidade: conviver com o banditismo e a marginalidade até a morte - esta, natural ou por assassinato em meio à guerra pelo tráfico de drogas. Apenas um personagem, Buscapé - o narrador do filme - tem destino diverso. Ao descobrir na fotografia um dom, depara-se também com a sua profissão.

Segundo o professor Jaílson Oliveira de Souza, que foi morador da favela da Maré no Rio de Janeiro e hoje é integrante do CEASM (Centro de Estudos e Ações Solidárias da Maré) é preciso atentar para o processo de construção e reconhecimento da identidade do jovem na cidade, assim como os pressupostos "adultocêntricos" dos discursos, que tratam a juventude, em especial a pobre, apenas na condição problema social e, portanto, objeto da ação do Estado ou das instituições sociais. Processo esse alimentado, em grande medida, pelos meios de comunicação.

O professor dá alguns exemplos da forma como a mídia trata a juventude brasileira, em especial a negra e pobre:

\begin{abstract}
Neste sentido, uma capa da revista semanal de maior circulação do Brasil, a Veja, me acompanha desde 2001: seguida da manchete "a periferia cerca a cidade", apresenta-se uma imagem na qual as construções de alvenaria, em cor escura - remetendo à visão de formigas saúvas em movimento - vão devorando gradativamente prédios brancos e limpos. O exemplo é ilustrativo do temor, atávico em amplos setores sociais das camadas médias e dominantes do Rio de Janeiro, São Paulo e outras metrópoles brasileiras, de que os "bárbaros" favelados invadam a "cidade", a polis, e esta seja dominada pelo caos. (SOUSA, 2005:15).
\end{abstract}

Outro exemplo dado pelo professor refere-se à cobertura dada pela grande imprensa a outro evento de larga expressão simbólica, ocorrido em abril de 2004, no Rio de Janeiro, corrobora a assertiva acima proposta:

Em uma noite daquele mês, aconteceu um conflito de grande visibilidade entre traficantes de drogas na Rocinha, antiga favela situada na área mais nobre da cidade. Tal conflito foi denominado pela grande imprensa como a "Guerra da Rocinha". Na tentativa de invasão daquela comunidade popular por um grupo armado foram assassinadas três pessoas: dois moradores locais e uma motorista que passava no túnel que une duas áreas nobres da cidade. (SOUSA, 2005:15).

Oliveira salienta que conflitos como esses, com a morte de várias pessoas inocentes, acontecem com relativa freqüência em localidades da periferia do Rio de 
Janeiro. O professor continua seu relato dizendo que, de acordo com a lógica natural da ordem social vigente, a morte da motorista, pertencente à "Classe média", que teve a fatalidade de passar de carro justamente na ocasião do conflito, teve muito mais destaque, protestos e lamentações do que a morte do casal de jovens da Rocinha. Para Oliveira, o fato mais impressionante então, foi a postura de responsabilização do conjunto de moradores da Rocinha pelo ocorrido.

Com efeito, um número expressivo de articulistas e leitores dos principais jornais da Cidade reivindicava, com indignação e rancor, o "direito de ir e vir" dos moradores da "cidade" - território no qual não incluem a favela - e questionava o direito de existência daquela comunidade, que abriga cerca de 80.000 pessoas e se constituiu há mais de 70 anos.

Outro exemplo do tratamento concedido aos jovens pobres na mídia parte de um dos três maiores jornais do Brasil: "Principal alvo da violência urbana, jovens de comunidades carentes começam a encontrar em escolas dos Estados do Rio de Janeiro e Pernambuco a oportunidade de se afastar das drogas e do crime" - (O Globo, 08/04/05).

A partir da leitura dessa manchete, o juízo que podemos fazer é que todos os jovens da periferia são potencialmente criminosos e, por isso, precisariam ter o seu tempo ocupado - sem importar muito como - a fim de não seguirem o caminho da criminalidade. $\mathrm{O}$ fato de existirem tão poucas pessoas, proporcionalmente falando, envolvidas com atos criminosos nas grandes cidades brasileiras - considerando-se as precárias condições de vida da população, historicamente - não é levado em conta na afirmação do discurso.

O que vemos, a partir dos exemplos infracitados e de tantos outros, é que a mídia estigmatiza a juventude, em especial os jovens negros, pobres e moradores da periferia. Ela os coloca numa invariável posição de criminosos. É como se a eles fosse vetado o direito a fazer outra coisa que não se envolver com tráfico de drogas, violência e crimes. O jovem oriundo das classes menos favorecidas, além de tantos direitos não respeitados, também não tem acesso ao direito à comunicação. Não se vê nos meios massivos, (salvo em casos de violência e tráfico de drogas) e tão pouco tem acesso à produção de informação.

Rosilene Alvim e Eugênia Paim no texto Os jovens suburbanos e a mídia: conceitos e preconceitos (2000), sugerem que a juventude suburbana, muitas vezes, é um problema social midiaticamente construído. A partir daí deve ser feita uma reflexão sobre a interação entre meios e sociedade. Isso porque, segundo as autoras, ao divulgarem a imagem estereotipada de jovens suburbanos como jovens ameaçadores, envolvidos com 
crimes, saques e sublevações, os meios de comunicação conduzem a representação do público sobre um tipo de protesto dos jovens das classes populares. Mesmo conscientes de que não se pode atribuir exclusivamente à imprensa a responsabilidade pelo modo como são encaminhadas essas notícias, já que o público mantém em relação a elas um tipo de voracidade que concorre para sua crescente exibição, é no campo próprio à mídia que elas se tornam espetaculares.

\section{3- Considerações finais}

$\mathrm{O}$ artigo pretendeu propor uma linha de reflexão sobre a complexa relação entre mídia e minorias no Brasil. Como vimos, através dos exemplos acima citados, os jovens não tem grande espaço na mídia brasileira. A eles geralmente estão destinadas as páginas policiais. Tal fato se agrava quando pensamos em jovens negros, pobres, moradores da periferia.

A mídia é, em grande parte, a responsável pelo estereótipo do jovem pobre, negro e conseqüentemente, criminoso. É como se a esse jovem fosse vetado o direito de produzir outra coisa que não violência.

Os dados sobre a situação atual da juventude pobre brasileira revelam a vulnerabilidade de nossos jovens e a importância de se fazer algo para resgatar sua cidadania. Como verificamos, os jovens excluídos, geralmente os pobres e negros, não têm, via de regra, o seu direito a cidadania respeitado. Partindo-se do conceito dado por Peruzzo: "Cidadania quer dizer participação, nos seus múltiplos sentidos e dimensões, incluindo a cidadania cultural, que perpassa o direito à liberdade de expressão." (2002, p.256), entende-se que a comunicação pode ser um instrumento para a promoção de cidadania juvenil.

E, para fazer da comunicação um instrumento de promoção da cidadania juvenil é preciso dar aos jovens um espaço diferente do das páginas policiais. É preciso buscar uma comunicação efetivamente democrática, em que todos tenham voz. 


\section{Referências Bibliográficas}

ALVIM, Rosilene; PAIM, Eugênia. Os jovens suburbanos e a mídia: conceitos e preconceitos. In: ALVIM, Rosilene; PAIM, Patrícia Gouveia (Orgs.). Juventude anos 90: conceitos, imagens, contextos. Rio de Janeiro, 2000.

ATHAYDE, Phydia de. Um tiro no futuro. Revista Carta Capital. Ano XII, no 424, 20 de dezembro de 2006.

LAHNI, Cláudia Regina; SILVA, Fernanda Coelho da silva; PEREIRA, Maria Fernanda França ; PELEGRINI, Mariana Zibordi. Aportes teóricos para um estudo sobre a participação na comunicação. 2007.

LAHNI, Cláudia Regina; SILVA, Fernanda Coelho da silva. A comunicação a serviço da cidadania e identidade de adolescentes. 2007.

MAIA, Aline Silva Correa. Jovens e Mídia: da periferia da cidade para o centro da página policial. CD I Colóquio Mídia e agenda Social da ANDI. Rio de Janeiro, 2007.

MASSI, Viviane Pereira. Comunicador pelos direitos da infância e da juventude, estudo de caso em Juiz de Fora. CDI, UFJF, 2001.

PAIVA, Anabela; Ramos, Sílvia. Mídia e Violência. Novas tendências na cobertura de criminalidade e segurança no Brasil. CESeC, Rio de Janeiro, 2007.

PERUZZO, Cicília Maria Krohling. Mídia Comunitária, Liberdade de Comunicação e Desenvolvimento. In: PERUZZO, Cicília Maria Krohling e FERREIRA DE ALMEIDA, Fernando. (Org.). Comunicação para a Cidadania, Intercom, 2002.

Internet

PEREGRINO, Mônica. www.multirio.rj.gov.br/sec21.com.br. Juventude e suas representações na mídia. Rio de janeiro, 17/01/2007. Acessado em 10 de dezembro de 2007.

SOUSA, Jaílson de Oliveira e. www.fazendomedia.com/novas.com.br. Juventude, favelas e os grandes meios de comunicação. Niterói, 15/11/2005. Acessado em 20 de dezembro de 2007. 